\title{
Volume-controlled versus pressure-controlled ventilation- volume guaranteed mode during one-lung ventilation
}

\author{
Seok Young Song, Jin Yong Jung, Min-Su Cho, Jong Hae Kim, Tae Ha Ryu, and Bong IL Kim \\ Department of Anesthesiology and Pain Medicine, Catholic University of Daegu School of Medicine, Daegu, Korea
}

Background: The purpose of this study was to investigate the changes in airway pressure and arterial oxygenation between ventilation modes during one-lung ventilation $(\mathrm{OLV})$ in patients undergoing thoracic surgery.

Methods: We enrolled 27 patients for thoracic surgery with OLV in the lateral decubitus position. The subjects received various modes of ventilation in random sequences during surgery, including volume-controlled ventilation (VCV) and pressure-controlled ventilation-volume guaranteed (PCV-VG) with a tidal volume (TV) of $8 \mathrm{ml} / \mathrm{kg}$ of actual body weight. Target-controlled infusion (TCI) with propofol and remifentanil was used for anesthesia induction and maintenance. After double-lumen endobronchial tube (DLT) insertion, the proper positioning of the DLT was assessed using a fiberoptic bronchoscope. Peak inspiratory pressure $\left(\mathrm{P}_{\text {peak }}\right)$, exhaled TV, and arterial blood gas were measured 30 min after each ventilation mode.

Results: $\mathrm{P}_{\text {peak }}$ was significantly reduced with the PCV-VG mode $\left(19.6 \pm 2.5 \mathrm{cmH}_{2} \mathrm{O}\right)$ compared with the VCV mode $\left(23.2 \pm 3.1 \mathrm{cmH}_{2} \mathrm{O}\right)(\mathrm{P}<0.000)$. However, no difference in arterial oxygen tension was noted between the groups (PCV$\mathrm{VG}, 375.8 \pm 145.1 \mathrm{mmHg}$; VCV, $328.1 \pm 123.7 \mathrm{mmHg})(\mathrm{P}=0.063)$. The exhaled TV was also significantly increased in PCV-VG compared with VCV ( $451.4 \pm 85.4$ vs. $443.9 \pm 85.9 \mathrm{ml}$; P = 0.035).

Conclusions: During OLV in patients with normal lung function, although PCV-VG did not provide significantly improved arterial oxygen tension compared with VCV, PCV-VG provided significantly attenuated airway pressure despite significantly increased exhaled TV compared with VCV. (Korean J Anesthesiol 2014; 67: 258-263)

Key Words: Airway pressure, Arterial oxygenation, One-lung ventilation, Pressure-controlled ventilation-volume guaranteed.

Received: March 14, 2014. Revised: 1st, May 16, 2014; 2nd, June 27, 2014. Accepted: June 30, 2014.

Corresponding author: Jin Yong Jung, M.D., Ph.D., Department of Anesthesiology and Pain Medicine, Catholic University of Daegu School of Medicine, 33, Duryugongwon-ro 17-gil, Nam-gu, Daegu 705-718, Korea. Tel: 82-53-650-4505, Fax: 82-53-650-4517, E-mail: jychung@cu.ac.kr (c) This is an open-access article distributed under the terms of the Creative Commons Attribution Non-Commercial License (http:// creativecommons.org/licenses/by-nc/3.0/), which permits unrestricted non-commercial use, distribution, and reproduction in any medium, provided the original work is properly cited. 


\section{Introduction}

One-lung ventilation (OLV) is essential for lung surgery $[1,2]$. The major concerns in OLV for anesthesiologists are the prevention of hypoxemia during surgery and the prevention of acute lung injury (ALI), which is associated with high postoperative mortality and morbidity [3]. To prevent hypoxemia in the use of low tidal volume (TV) of less than $8 \mathrm{ml} / \mathrm{kg}$, which results in atelectasis, increased TVs, such as $10-12 \mathrm{ml} / \mathrm{kg}$, can be employed even during OLV [4,5]. Although, the incidence of hypoxemia during OLV has recently dropped below $1 \%$ given advances in anesthesia drugs and equipment [6], attention has been given to reduce or avoid pressure- or volume-induced ALI during thoracic surgery [3]. Therefore, decreased airway pressure during OLV aids in reducing the risk of ALI against barotraumas and improving oxygenation by reducing the shunt fraction of the dependent lung as increased airway pressure of the dependent lung converts blood flow from the dependent lung to the nondependent lung against hypoxic pulmonary vasoconstriction.

A controversy exists as to which ventilation mode is better for oxygenation during OLV with regard to pressure-controlled ventilation $(\mathrm{PCV})$ versus volume-controlled ventilation $(\mathrm{VCV})$ [7-10]. PCV enhances oxygenation more than VCV given its initial high peak inspiratory flow rates and its rapidly decelerating flow pattern [11]. However, this high peak inspiratory flow rate might also provoke lung injury via shearing and traction forces on the alveoli [12].

A new ventilation mode, PCV with volume-guaranteed mode (PCV-VG), has been recently introduced the field of anesthesiology; in PCV-VG mode, the ventilator automatically regulates the peak inspiratory pressure $\left(\mathrm{P}_{\text {peak }}\right)$ to achieve a set TV that operators (anesthesiologists) seek to deliver [13]. To determine the optimal inspiratory pressure for PCV-VG mode, a set TV is initially delivered. Upon the calculation of the patient's lung compliance and inspiratory pressure, the PCV-VG mode delivers adequate TV with an inspiratory pressure adjusted within \pm $3 \mathrm{cmH}_{2} \mathrm{O}$ [13].

The primary goal of this study was to investigate whether PCV-VG might improve oxygenation compared with VCV during OLV in patients undergoing thoracic surgery. The secondary goal of this study was to investigate whether PCV-VG could decrease $\mathrm{P}_{\text {peak }}$ or $\mathrm{P}_{\text {mean }}$, thereby maintaining or increasing exhaled tidal volume $\left(\mathrm{TV}_{\mathrm{E}}\right)$ during OLV.

\section{Materials and Methods}

We began this study after receiving approval from the Institutional Review Board of our hospital and obtaining informed consent from all the patients. Twenty-seven patients who were classified as American Society of Anesthesiologists physical status 1 and 2 and underwent thoracic surgery in the lateral decubitus position with at least $1 \mathrm{~h}$ OLV were enrolled (Table 1, Fig. 1). The exclusion criteria were previous lobectomy, uncompensated cardiac disease, tracheostomy state, and predicted forced expiratory volume in 1 second (FEV1) below 70\%. All patients were intramuscularly injected with $0.2 \mathrm{mg}$ glycopyrrolate and $1 \mathrm{mg}$ midazolam as premedication $30 \mathrm{~min}$ before arriving in the operating room. The patients were furnished with electrocardiogram (ECG), noninvasive blood pressure, pulse oximetry, and bispectral index (BIS) monitoring equipment before the induction of anesthesia. Anesthesia was induced and maintained with an effect-site concentration of $4 \mu \mathrm{g} / \mathrm{ml}$ propofol and $4 \mathrm{ng} / \mathrm{ml}$ remifentanil using target controlled infusion (TCI). After loss of consciousness, $0.6 \mathrm{mg} / \mathrm{kg}$ rocuronium was administered for intubation, and $0.08 \mathrm{mg} / \mathrm{kg} / \mathrm{hr}$ vecuronium infusion was followed $30 \mathrm{~min}$ after intubation. All patients were intubated with a double-lumen endobronchial tube (DLT, Silbroncho ${ }^{\circledR}$, Fuji System Corp, Tokyo, Japan), and the proper position of the DLT was confirmed using a fiberoptic bronchoscope. All of the patients were intubated with left-side DLT if there was no contraindication. After intubation, a radial artery cannulation was performed on the contralateral side arm of the operation, and a central venous catheter was placed in the ipsilateral subclavian vein. Initially, two-lung ventilation with VCV was performed using 1.0 fraction of inspired oxygen concentration $\left(\mathrm{FiO}_{2}\right)$, a TV of $8 \mathrm{ml} / \mathrm{kg}$ of actual body weight, and $12 / \mathrm{min}$ respiration rate. The respiration rate was adjusted to maintain an end-tidal carbon dioxide concentration $\left(\mathrm{ETCO}_{2}\right)$ of $35-40 \mathrm{mmHg}$. After changing the patient to a lateral decubitus position, the location of the DLT was reassessed with a fiberoptic bronchoscope. OLV was subsequently performed with VCV or PCV-VG (Avance, GE healthcare, Wauwatosa, WI, USA) according to an allocation sequence. An independent statistician randomized the ventilation

Table 1. Demographic Variables

\begin{tabular}{lc}
\hline Age $(\mathrm{yr})$ & $63.6 \pm 9.7$ \\
Sex $(\mathrm{M} / \mathrm{F})$ & $15 / 12$ \\
Height $(\mathrm{cm})$ & $162.8 \pm 10.9$ \\
Weight $(\mathrm{kg})$ & $60.6 \pm 10.5$ \\
Body mass index $\left(\mathrm{kg} / \mathrm{m}^{2}\right)$ & $22.8 \pm 2.8$ \\
Duration of operation (min) & $307.9 \pm 68.2$ \\
Preoperative FVC (\% of predictive) & $101.3 \pm 24.4$ \\
Preoperative FEV1 (\% of predictive) & $107.3 \pm 33.1$ \\
Diagnosis & \\
$\quad$ Lung cancer & 23 \\
$\quad$ Mediastinal mass & 2 \\
$\quad$ Esophageal cancer & 2 \\
Operation site (left/right) & $15 / 12$ \\
Surgical approach & \\
$\quad$ VATS & 14 \\
$\quad$ Open thoracotomy & 13 \\
\hline FVC: forced vital capacity, FEV1: forced expiratory volume in 1 second, \\
VATS: video-assisted thoracoscopic surgery.
\end{tabular}




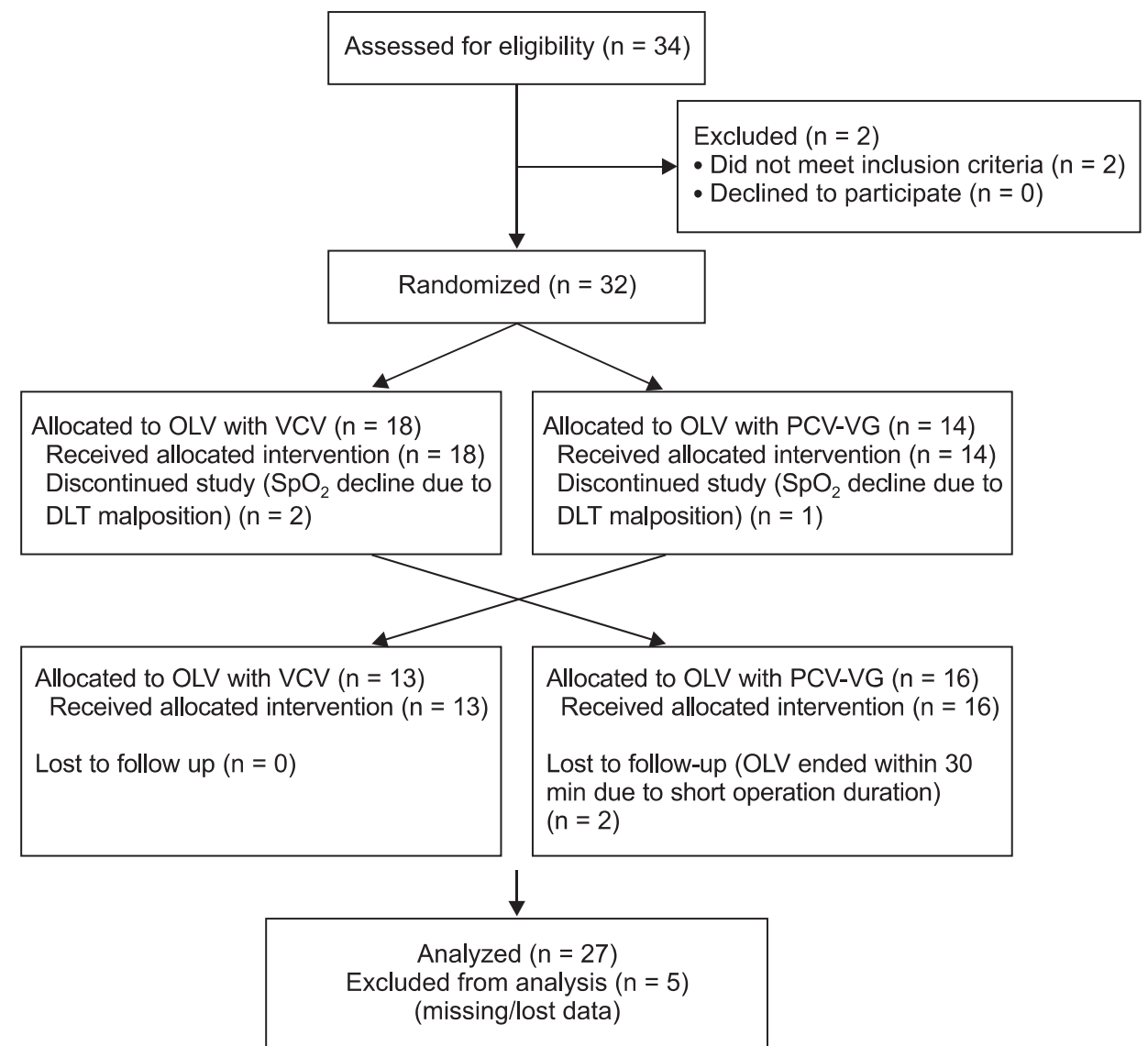

Fig. 1. Consort diagram depicts the flow of participants. sequence using a computerized random number generator. VCV was set to deliver a TV of $8 \mathrm{ml} / \mathrm{kg}$ of actual body weight without positive end-expiratory pressure (PEEP), and the respiration rate was adjusted to maintain an $\mathrm{ETCO}_{2}$ of $35-40 \mathrm{mmHg}$ using $1.0 \mathrm{FiO}_{2}$. The maximum airway pressure $\left(\mathrm{P}_{\text {max }}\right)$, at which time the ventilator will alarm and end inspiration, was adjusted to 40 $\mathrm{cmH}_{2} \mathrm{O}$. An inspiration to expiration ratio of $1: 2$ was used, and no inspiratory time pause was used. PCV-VG was performed using $1.0 \mathrm{FiO}_{2}$, a TV of $8 \mathrm{ml} / \mathrm{kg}$ of actual body weight without PEEP, $40 \mathrm{cmH}_{2} \mathrm{O} \mathrm{P}_{\max }$, and an inspiration to expiration ratio of $1: 2$; the respiration rate was adjusted to maintain an $\mathrm{ETCO}_{2}$ of 35-40 $\mathrm{mmHg}$. The rise rate, which indicates how quickly the ventilator reaches the targeted airway pressure, was adjusted to 5 sec. In the PCV-VG mode, the present anesthetic machine delivers the first breath to the patient using a VCV setting to identify the patient's lung compliance, and then the inspiratory pressure level is automatically calculated and determined for the subsequent breaths in the PCV-VG setting. The $\mathrm{P}_{\text {peak }}$, mean inspiratory pressure $\left(\mathrm{P}_{\text {mean }}\right), \mathrm{TV}_{\mathrm{E}}$, systolic and diastolic blood pressures (SBP, DBP), heart rate (HR), arterial oxygen tension $\left(\mathrm{PaO}_{2}\right)$, and arterial carbon dioxide tension $\left(\mathrm{PaCO}_{2}\right)$ were measured and recorded after performing each mode of mechanical ventilation for $30 \mathrm{~min}$ in the lateral decubitus position. Afterwards, the ventilation was changed to another mode and maintained until the surgery was completed. When the ventilation mode was changed from VCV to PCV-VG or from PCV-VG to VCV $30 \mathrm{~min}$ after OLV, the TV and respiration rate of the previous mode were maintained. Thirty minutes after changing the ventilation mode, all measurements were performed again. When the peripheral oxygen saturation $\left(\mathrm{SpO}_{2}\right)$ decreased below $90 \%$ or $\mathrm{PaO}_{2}$ decreased below $80 \mathrm{mmHg}$, both of which are defined as hypoxemia, the experiment was terminated. When hypoxemia occurred, two-lung ventilation with $1.0 \mathrm{FiO}_{2}$ was performed, and the patient was excluded from this study. Hypoxemia was treated according to standard hypoxemia treatment protocols, including DLT position readjustment using a fiberoptic bronchoscope, lung recruitment maneuver, change of TV, and the application of PEEP or continuous positive airway pressure.

A twenty five percent improvement in $\mathrm{PaO}_{2}$ was considered clinically relevant although a previous study revealed an approximate 65.7\% improvement in $\mathrm{PaO}_{2}$ [14]. A sample-size of 24 patients provides a statistical power of $80 \%$ at a significance level of 0.05 . Given an expected $10 \%$ dropout rate, we ultimately included 27 patients in this study. Statistical analyses were performed using SPSS for Windows, version 17.0 (SPSS, Chicago, IL, USA). All of the measured values are presented as means \pm 
standard deviations. The measured variables for both VCV and PCV-VG were compared using paired t-tests. A $\mathrm{P}$ value $<0.05$ was considered statistically significant.

\section{Results}

PCV-VG resulted in an increased $\mathrm{PaO}_{2}$ in $63 \%$ of patients (17/27) and a reduced $\mathrm{PaO}_{2}$, in 33.3\% (9/27) of patients compared with $\mathrm{PaO}_{2}$ in $\mathrm{VCV}$, whereas PCV-VG results in no difference in $3.3 \%$ of patients (1/27). However, PCV-VG did not provide a significantly increased $\mathrm{PaO}_{2}$ compared with VCV during $\operatorname{OLV}(\mathrm{P}=0.063)$.

PCV-VG resulted in a significantly reduced $\mathrm{P}_{\text {peak }}$ compared with VCV during OLV $\left(19.6 \pm 2.5\right.$ vs. $23.2 \pm 3.1 \mathrm{cmH}_{2} \mathrm{O}$; $\mathrm{P}<0.001)$. However, the $\mathrm{P}_{\text {mean }}$ for PCV-VG was significantly increased compared with VCV $\left(9.7 \pm 1.3\right.$ vs. $8.9 \pm 1.4 \mathrm{cmH}_{2} \mathrm{O}$; $\mathrm{P}<0.001$ ) during $\mathrm{OLV}$. The $\mathrm{TV}_{\mathrm{E}}$ was also significantly higher for PCV-VG than VCV (451.4 \pm 85.4 vs. $443.9 \pm 85.9 \mathrm{ml}$; $=0.035)$.

When adopting a new concept, the $\mathrm{P}_{\text {peak }} / \mathrm{TV}_{\mathrm{E}}$ and $\mathrm{P}_{\text {mean }} / \mathrm{TV}_{\mathrm{E}}$, which represent the pressure necessary to produce $1 \mathrm{ml}$ of TV, should be assessed. The $\mathrm{P}_{\text {peak }} / \mathrm{TV}_{\mathrm{E}}$ was significantly reduced for PCV-VG compared with VCV $(0.044 \pm 0.006$ vs. $0.053 \pm 0.007$ $\left.\mathrm{cmH}_{2} \mathrm{O} / \mathrm{ml} ; \mathrm{P}<0.001\right)$. However, the $\mathrm{P}_{\text {mean }} / \mathrm{TV}_{\mathrm{E}}$ for PCV-VG was significantly increased compared with VCV $(0.022 \pm 0.003$

Table 2. Airway Pressures and Exhaled Tidal Volumes in the Various Ventilator Modes during One-lung Ventilation

\begin{tabular}{lcc}
\hline & VCV & PCV-VG \\
\hline $\mathrm{P}_{\text {peak }}\left(\mathrm{cmH}_{2} \mathrm{O}\right)$ & $23.2 \pm 3.1$ & $19.6 \pm 2.5^{*}$ \\
$\mathrm{P}_{\text {mean }}\left(\mathrm{cmH}_{2} \mathrm{O}\right)$ & $8.9 \pm 1.4$ & $9.7 \pm 1.3^{*}$ \\
$\mathrm{TV}_{\mathrm{E}}(\mathrm{ml})$ & $443.9 \pm 85.9$ & $451.4 \pm 85.4^{\dagger}$ \\
$\mathrm{P}_{\text {peak }} / \mathrm{TV}_{\mathrm{E}}\left(\mathrm{cmH}_{2} \mathrm{O} / \mathrm{ml}\right)$ & $0.053 \pm 0.007$ & $0.044 \pm 0.006^{*}$ \\
$\mathrm{P}_{\text {mean }} / \mathrm{TV}_{\mathrm{E}}\left(\mathrm{cmH}_{2} \mathrm{O} / \mathrm{ml}\right)$ & $0.020 \pm 0.003$ & $0.022 \pm 0.003^{*}$ \\
\hline
\end{tabular}

Data are presented as means $\pm \mathrm{SD}$. $\mathrm{P}_{\text {peak }}$ : peak inspiratory pressure, $\mathrm{P}_{\text {mean }}$ : mean inspiratory pressure, $\mathrm{TV}_{\mathrm{E}}$ : exhaled tidal volume, $\mathrm{VCV}$ : volume-controlled ventilation, $\mathrm{PCV}-\mathrm{VG}$ : pressure-controlled ventilationvolume guaranteed. $* \mathrm{P}<0.001$ compared with $\mathrm{VCV},{ }^{\dagger} \mathrm{P}<0.05$ compared with VCV.

Table 3. Arterial Blood Gas Values in Volume-controlled Ventilation and Pressure-controlled Ventilation-volume Guaranteed during Onelung Ventilation

\begin{tabular}{lcc}
\hline & VCV & PCV-VG \\
\hline $\mathrm{PaO}_{2}(\mathrm{mmHg})$ & $328.1 \pm 123.7$ & $375.8 \pm 145.1$ \\
$\mathrm{PaCO}_{2}(\mathrm{mmHg})$ & $38.5 \pm 5.4$ & $38.5 \pm 5.6$ \\
$\mathrm{SaO}_{2}(\%)$ & $99.7 \pm 0.5$ & $99.5 \pm 0.8$ \\
$\mathrm{pH}$ & $7.4 \pm 0.1$ & $7.4 \pm 0.1$ \\
Hematocrit $(\%)$ & $32.4 \pm 7.5$ & $33.3 \pm 4.2$ \\
\hline
\end{tabular}

Data are presented as means \pm SD. No significant differences were noted between the groups. VCV: volume-controlled ventilation, PCV-VG: pressure-controlled ventilation-volume guaranteed. vs. $0.020 \pm 0.003 \mathrm{cmH}_{2} \mathrm{O} / \mathrm{ml} ; \mathrm{P}<0.001$ ) (Table 2).

No differences in $\mathrm{PaCO}_{2}$, arterial oxygen saturation $\left(\mathrm{SaO}_{2}\right)$, and hematocrit were noted between VCV and PCV-VG (Table 3). Hemodynamic variables, such as $\mathrm{BP}$ and $\mathrm{HR}$, did not differ between VCV and PCV-VG (Table 4).

\section{Discussion}

This study compared the differences in arterial oxygenation, airway pressure, and $\mathrm{TV}_{\mathrm{E}}$ between VCV and PCV-VG to clarify the differences in the oxygenation profile and airway dynamics based on the ventilation mode during OLV for thoracic surgery. The results indicate that, although PCV-VG decreases $\mathrm{P}_{\text {peak }}$, it does not provide enhanced arterial oxygenation compared with VCV during OLV in patients undergoing thoracic surgery. However, this study indicates that PCV-VG attenuates airway pressure against the enhanced $\mathrm{TV}_{\mathrm{E}}$ during this period.

Theoretically, PCV-VG is operated as PCV, but a target TV is also set and well maintained. Therefore, PCV-VG always assures the TV, which is typically affected by the patient's airway compliance during PCV. The attenuated airway pressure for the enhanced $\mathrm{TV}_{\mathrm{E}}$ in this study appears to be due to the proportion of the inspiratory flow. Although PCV-VG has advantages compared with $\mathrm{PCV}$, few reports have compared the effectiveness of PCV-VG with VCV during OLV.

The goals of anesthetic management in thoracic surgery are to prevent hypoxia and ALI related to OLV [3]. We thought that decreasing $\mathrm{P}_{\text {peak }}$ using PCV-VG could reduce the risk of barotrauma and improve oxygenation by reducing the shunt flow from the dependent lung to the nondependent lung. However, no observed changes in arterial oxygenation between PCV-VG and VCV were noted in this study. These findings are inconsistent with those of Boules and Ghobrial [14]. These researchers divided 40 patients into two groups, the PCV-VG and VCV groups, for thoracic surgery in the lateral decubitus position and reported that $\mathrm{PaO}_{2}$ in the PCV-VG group was significantly increased for OLV compared with the VCV group. They also demonstrated that the $\mathrm{P}_{\text {peak }}$ and $\mathrm{P}_{\text {mean }}$ were significantly reduced in the PCV-VG group compared with the VCV group. The authors

Table 4. Hemodynamic Variables in the Various Ventilator Modes during One-lung Ventilation

\begin{tabular}{lcc}
\hline & VCV & PCV-VG \\
\hline SBP (mmHg) & $134.2 \pm 18.9$ & $130.0 \pm 15.2$ \\
DBP (mmHg) & $69.9 \pm 11.8$ & $70.6 \pm 9.8$ \\
Heart rate (beats/min) & $69.6 \pm 12.4$ & $67.9 \pm 12.4$ \\
\hline
\end{tabular}

Data are presented as means \pm SD. No significant differences were noted between the groups. SBP: systolic blood pressure, DBP: diastolic blood pressure, VCV: volume-controlled ventilation, PCV-VG: pressure-controlled ventilation-volume guaranteed. 
explained that PCV-VG improved oxygenation approximately $65.7 \%$ during OLV due to a decrease in the vascular resistance of the dependent lung, which resulted in decreased shunt flow from the dependent to the nondependent lung. In the present study, despite the fact that the $\mathrm{P}_{\text {peak }}$ in PCV-VG was significantly reduced compared with $\mathrm{VCV}$, the $\mathrm{P}_{\text {mean }}$ was significantly increased with PCV-VG compared with VCV. It is unclear why our $\mathrm{P}_{\text {mean }}$ results differ from those of Boules and Ghobrial [14]. However, it is possible that differences in ventilator settings, such as the inspiratory pause, or the patient's pulmonary function might affect PCV-VG's impact on $\mathrm{P}_{\text {mean }}$. The present study did not demonstrate enhanced oxygenation with PCV-VG. Although it is unclear why this study did not demonstrate improved oxygenation in PCV-VG compared with VCV, the body mass indices of the patients in our study differed from those in the study by Boules and Ghobrial. In addition, preoperative respiratory function was better in present study compared with the Boules and Ghobrial study. Although a significant difference was not evident, $66 \%$ of patients experienced better oxygenation with PCV-VG, and $33 \%$ of patients experienced worse oxygenation with PCV-VG in present study. The reasons for the difference between the responders and non-responders in terms of oxygenation improvement with PCV-VG during OLV were unclear in this study, and further research is necessary to determine the exact causes and correlation factors.

Numerous reports have compared PCV and VCV [7-10]. Recently, the effects of PCV on intraoperative arterial oxygenation during OLV have demonstrated conflicting outcomes [7,8]. Tugrul et al. [7] reported that PCV improves oxygenation during OLV compared with VCV. They found that the higher plateau pressure in VCV increased pulmonary shunt flow, which was attributed to oxygenation deterioration. Additionally, they noted that patients with improved arterial oxygenation with PCV during OLV demonstrated reduced forced vital capacity in general. In other words, patients with restrictive pulmonary disease might achieve better results with PCV than with VCV during OLV. In contrast, Unzueta et al. [8] demonstrated that PCV for OLV did not lead to improved oxygenation compared with VCV for patients with good preoperative pulmonary function. However, they suggested that an advantage of PCV during OLV is decreased $\mathrm{P}_{\text {peak }}$. In the present study, one reason why PCV-VG did not improve oxygenation during OLV might be that the subjects in this experiment were patients with good pulmonary function. PCV-VG was operated similar to PCV except in the guarantee of TV and thus minute ventilation. Thus, further studies might be needed to determine whether PCV-VG is effective during OLV in patients with restrictive pulmonary disease.

It is controversial which TV is best during OLV. Traditionally, textbooks recommend high TV (10-12 ml/kg) [4]. Overinflation with a high TV could increase pulmonary vascular resistance in the dependent lung, and a low TV of less than $8 \mathrm{ml} /$ $\mathrm{kg}$ without PEEP could predispose the patient to atelectasis [5]. Among the causes of ALI, increased airway pressure due to high TV causes the pulmonary parenchyma to over-stretch, which induces ALI $[15,16]$. However, it has been reported that TVs of less than $9 \mathrm{ml} / \mathrm{kg}$ do not induce ALI [17]. Therefore, a TV of $8 \mathrm{ml} / \mathrm{kg}$ was used in this study.

The incidence of ALI after lung surgery is increased after pneumonectomy compared with lobectomy [18]. Theoretically, ALI results in pulmonary edema, which increases with large resection ranges or high intraoperative ventilation pressures [19]. Although the mechanisms that induce ALI are diverse and complicated, decreasing the $\mathrm{P}_{\text {peak }}$ using PCV-VG rather than VCV might help to prevent ALI.

A limitation of this study was that surgical manipulation potentially affected the arterial oxygenation. Despite the fact that the ventilation sequence was randomly allocated, the surgical locations might have been different, and pulmonary artery occlusion might have affected the shunt fraction. In addition, ideal body weight was not used to calculate TV. Because airway pressure correlates with TV, the airway pressure in patients with a high body mass index was increased compared with patients with a normal body mass index. Increased airway pressure in the dependent lung could divert blood to the nondependent lung. Thus, increased pressure might increase the shunt fraction and decrease arterial oxygenation.

In conclusion, the PCV-VG mode did not provide significantly improved oxygenation compared with the VCV mode during OLV for patients with normal pulmonary function. However, this ventilation mode during OLV attenuated airway pressure despite the increase tidal volume compared with the VCV mode. Further investigation might be indicated to determine the possible efficacy of this ventilation mode in attenuating ALI by reducing airway pressure during OLV.

\section{References}

1. Seok JH, Kim EJ, Ban JS, Lee SG, Lee JH, Seo DM, et al. Severe desaturation while attempting one-lung ventilation for congenital cystic adenomatoid malformation with respiratory distress syndrome in neonate -A case report-. Korean J Anesthesiol 2013; 65: 80-4.

2. Lee DK, Kim YM, Kim HZ, Lim SH. Right upper lobe tracheal bronchus: anesthetic challenge in one-lung ventilated patients -A report of three cases-. Korean J Anesthesiol 2013; 64: 448-50. 
3. Licker M, de Perrot M, Spiliopoulos A, Robert J, Diaper J, Chevalley C, et al. Risk factors for acute lung injury after thoracic surgery for lung cancer. Anesth Analg 2003; 97: 1558-65.

4. Slinger PD, Campos JH. Anesthesia for thoracic surgery. In: Miller's Anesthesia. 7th ed. Edited by Miller RD, Eriksson LI, Fleisher LA, Wiener-Kronish JP, Young WL: Philadelphia, Churchill Livingstone. 2010, p 1849.

5. Gal TJ. Con: low tidal volumes are indicated during one-lung ventilation. Anesth Analg 2006; 103: 271-3.

6. Brodsky JB, Lemmens HJ. Left double-lumen tubes: clinical experience with 1,170 patients. J Cardiothorac Vasc Anesth 2003; 17: $289-98$.

7. Tuğrul M, Camci E, Karadeniz H, Sentürk M, Pembeci K, Akpir K. Comparison of volume controlled with pressure controlled ventilation during one-lung anaesthesia. Br J Anaesth 1997; 79: 306-10.

8. Unzueta MC, Casas JI, Moral MV. Pressure-controlled versus volume-controlled ventilation during one-lung ventilation for thoracic surgery. Anesth Analg 2007; 104: 1029-33.

9. Heimberg C, Winterhalter M, Strüber M, Piepenbrock S, Bund M. Pressure-controlled versus volume-controlled one-lung ventilation for MIDCAB. Thorac Cardiovasc Surg 2006; 54: 516-20.

10. Prella M, Feihl F, Domenighetti G. Effects of short-term pressure controlled ventilation on gas exchange, airway pressures, and gas distribution in patients with acute lung injury/ARDS: comparison with volume-controlled ventilation. Chest 2002; 122:1382-8.

11. MacIntyre NR. New modes of mechanical ventilation. Clin Chest Med 1996; 17: 411-21.

12. Maeda Y, Fujino Y, Uchiyama A, Matsuura N, Mashimo T, Nishimura M. Effects of peak inspiratory flow on development of ventilatorinduced lung injury in rabbits. Anesthesiology 2004; 101: 722-8.

13. Keszler M. Volume-targeted ventilation. Early Hum Dev 2006; 82: 811-8.

14. Boules NS, Ghobrial HZ. Efficiency of the newly introduced ventilatory mode "pressure controlled ventilation-volume guaranteed" in thoracic surgery with one lung ventilation. Egypt J Anaesth 2011; 27: 113-9.

15. Tsuno K, Miura K, Takeya M, Kolobow T, Morioka T. Histopathologic pulmonary changes from mechanical ventilation at high peak airway pressures. Am Rev Respir Dis 1991; 143: 1115-20.

16. Parker JC, Hernandez LA, Peevy KJ. Mechanisms of ventilator induced lung injury. Crit Care Med 1993; 21: 131-43.

17. Fernandez-Perez ER, Sprung J, Afessa B, Warner DO, Vachon CM, Schroeder DR, et al. Intraoperative ventilator settings and acute lung injury after elective surgery: a nested case control study. Thorax 2009; 64: 121-7.

18. Slinger P. Pro: low tidal volume is indicated during one-lung ventilation. Anesth Analg 2006; 103: 268-70.

19. Stewart DJ, Martin-Uncar AE, Edwards JG, West K, Waller DA. Extra-pleural pneumonectomy for malignant mesothelioma: the risks of induction chemotherapy, right-sided procedures and prolonged operations. Eur J Cardiothorac Surg 2005; 27: 373-8. 